\title{
Differential effects of nanoselenium doping on healthy and cancerous osteoblasts in coculture on titanium
}

This article was published in the following Dove Press journal:

International Journal of Nanomedicine

7 May 2010

Number of times this article has been viewed

Phong A Tran'

Love Sarin ${ }^{2}$

Robert $\mathrm{H}$ Hurt ${ }^{2}$

Thomas J Webster ${ }^{2,3}$

'Physics Department, ${ }^{2}$ Division of Engineering, ${ }^{3}$ Department of Orthopedic Surgery, Brown University, Providence, RI, USA
Correspondence: Thomas JWebster Division of Engineering and Department of Orthopedic Surgery, Brown University, Providence, RI 02912, USA

Tel +I 40I 863323 I8

Email thomas_webster@brown.edu
Abstract: In the present study, selenium (Se) nanoclusters were grown through heterogeneous nucleation on titanium (Ti) surfaces, a common orthopedic implant material. Normal healthy osteoblasts (bone-forming cells) and cancerous osteoblasts (osteosarcoma) were cultured on the Se-doped surfaces having three different coating densities. For the first time, it is shown that substrates with Se nanoclusters promote normal osteoblast proliferation and inhibit cancerous osteoblast growth in both separate (mono-culture) and coculture experiment. This study suggests that Se surface nanoclusters can be properly engineered to inhibit bone cancer growth while simultaneously promoting the growth of normal bone tissue.

Keywords: selenium, coating, nanotechnology, biomaterials, orthopedics, bone cancer

\section{Introduction}

It is estimated that 2,380 individuals will be diagnosed with bone and joint cancer and 1,470 individuals will die from primary bone and joint cancer in 2008 in the US. ${ }^{1}$ Primary bone cancer is rare, as usually bone cancer is a result of the spread of cancer from other organs (such as the lungs, breasts and prostate). A common technique to treat bone cancer is the surgical removal of cancerous tissue followed by insertion of an orthopedic implant to restore patient functions. However, sometimes the cancerous cells are not completely removed. Therefore, it would be beneficial to have implants specifically designed to prevent the occurrence and reoccurrence of bone cancer and promote healthy bone tissue growth. Unfortunately, current materials used as orthopedic implants (such as titanium, stainless steel, and ultra-high-molecular-weight polyethylene) do not possess anticancer properties and, thus, have no inherent mechanisms to keep cancer from reoccurring.

Recently, we have introduced a new anticancer bone implant, which combines the carcinostatic activity of selenium with the well known mechanical properties of the traditional implant material, titanium. ${ }^{2,3}$ This novel anticancer orthopedic implant material was created by heterogenous nucleation of selenium nanoclusters on the surface of titanium. It was shown in separate culture experiments that selenium doping on surfaces increased healthy osteoblast and decreased cancerous osteoblast functions. ${ }^{2}$ The objective of the present in vitro coculture study on this novel material was to simultaneously: (i) promote normal bone cell functions and (ii) inhibit cancerous bone cell functions. As a trace element in humans and animals, Se plays important roles in many processes such as antioxidant defense systems, thyroid hormone metabolism and redox control of cell reactions. ${ }^{4}$ Selenium consumed in excess of the nutritional requirement 
can inhibit and/or retard carcinogenesis in animals. ${ }^{5}$ High levels of Se in the blood $(\sim 154 \mu \mathrm{g} / \mathrm{mL})$ have been correlated with reduced numbers of cancers including pancreatic, gastric, lung, nasopharyngeal, breast, uterine, respiratory, digestive, hematological and gynecological. ${ }^{6}$ Selenium has also been shown to inhibit the growth of many cancerous cell lines in vitro. For example, culture media enriched with Se in the form of sodium selenite, selenomethionine, or selenocysteine inhibited malignant mesothelioma (MM) cells in a dose-dependent manner via apoptosis-related mechanisms to SEP15 which is a gene encoding a $15-\mathrm{kDa}$ Se-containing protein. ${ }^{7}$ However, normal mesothelial cells were not affected. In spite of a great number of studies on the effect of selenium compounds on cancer, there are very few experiments focusing on the effect of substrate-bound elemental Se nanoclusters on cancer growth. The mechanisms of Se-based chemoprevention are also complex and incompletely understood. ${ }^{8}$

To promote normal osteoblast functions, we focused on introducing selenium in a manner that also produces a nanostructured surface, ${ }^{3}$ since numerous studies have shown increased osteoblast functions (including adhesion, proliferation, differentiation, protein synthesis and calcium-containing mineral deposition) on nanorough surfaces compared to microrough, nanosmooth surfaces. ${ }^{9-14}$ It was also shown that initial protein interactions from serum on nanostructured ceramics ${ }^{11,14}$ and nanophase metals ${ }^{10}$ was optimal, leading to greater osteoblast functions. The increased osteoblast functions on nanophase compared to micron, conventional ceramics was also independent of surface chemistry and material crystalline phase. ${ }^{13}$

Here, we demonstrate through both mono- and coculture experiments that Se nanoclusters heterogeneously nucleated on titanium orthopedic material surfaces have the potential to achieve the dual goals of increasing normal bone cell functions and decreasing cancerous bone cell growth.

\section{Materials and methods Materials}

Titanium (Ti) substrates (Alfa Aesar, Ward Hill, MA, USA) were individually degreased and sonicated in acetone and ethanol for $10 \mathrm{~min}$. Degreased substrates were then sterilized by autoclaving at $121^{\circ} \mathrm{C}$ for $30 \mathrm{~min}$. Cleaned and sterilized substrates were used as a base substrate for the colloidal decoration with Se nanoclusters. The substrates were exposed to 4:1 molar mixtures of glutathione (GSH, reduced form; TCI America, Portland, OR, USA) and sodium selenite $\left(\mathrm{Na}_{2} \mathrm{SeO}_{3}\right.$; Alfa Aesar) in the concentration ranges shown in Table 1.

Three different solution concentrations (Table 1) were used to achieve different doses denominated as low, medium, and high Se doses. After a gentle mixing of the solutions in the reaction beaker, $1 \mathrm{M} \mathrm{NaOH}$ was introduced to bring the $\mathrm{pH}$ into the alkaline regime. The reaction mixture was once again gently mixed and left undisturbed for $10 \mathrm{~min}$. The substrates were withdrawn from the beaker and rinsed in deionized water. The uncoated and coated substrates were exposed to ultraviolet (UV) light for 24 hours on each side to sterilize them before use in cell experiments.

\section{Surface characterization}

Surfaces of the uncoated and Se-coated Ti substrates were visualized using a scanning electron microscope (SEM; LEO 1530VP FE-4800) with an accelerating voltage from $3 \mathrm{kV}$ to $10 \mathrm{kV}$. To test the strength of Se nanocluster attachment, the coated substrates were subjected to sonication for $10 \mathrm{~min}$ at $90 \mathrm{~W}$ (ultrasonic cleaner 75D, VWR).

Surface hydrophilicity/hydrophobicity was also determined in this study by measuring the contact angle of water on the substrates of interest using a contact angle analyzer (EasyDrop; Krüss, Hamburg, Germany). For that, $2 \mu \mathrm{L}$ water drops were dispensed using appropriate software (Drop Shape

Table I Reagent volumes used in the colloidal synthesis of Se nanoclusters in the presence of $\mathrm{Ti}^{2}$

\begin{tabular}{llll}
\hline Reagent & Preparation method & & \\
\cline { 2 - 4 } & "[Se] = 0.42 mM & [Se] = 0.84 mM & [Se] I.68 mM \\
& “Low Dose” & "Medium Dose” & "High Dose” \\
\hline Deionized water & $14.5 \mathrm{ml}$ & $14 \mathrm{ml}$ & $13 \mathrm{ml}$ \\
$100 \mathrm{mM}$ glutathione (GSH) & $0.25 \mathrm{ml}$ & $0.5 \mathrm{ml}$ & $1 \mathrm{ml}$ \\
$25 \mathrm{mM} \mathrm{Na} \mathrm{SeO}_{3}$ & $0.25 \mathrm{ml}$ & $0.5 \mathrm{ml}$ & $1 \mathrm{ml}$ \\
Final volume & $15 \mathrm{ml}$ & $15 \mathrm{ml}$ & $15 \mathrm{ml}$ \\
\hline
\end{tabular}

Notes: ${ }^{*}[\mathrm{Se}]=$ Final concentration of Se in the colloidal synthesis solution. Abbreviations: Se, selenium; Ti, titanium. 
Analysis; Krüss) and contact angles were measured every second and averaged within the first 15 seconds of dispensing. Surface energies of the uncoated Ti and nanoselenium-coated Ti were determined from the measured contact angles using appropriate software (Drop Shape Analysis).

\section{Cell assays}

Separate cell culture assays

To investigate the density of normal healthy noncancerous osteoblasts and cancerous osteoblasts on the uncoated and Se-coated Ti substrates, either primary human calvarial osteoblasts (bone-forming cells; ScienCell Research Laboratories, Carlsbad, CA, USA) in appropriate osteoblast cell culture medium (ObM; ScienCell Research Laboratories) or mouse osteosarcoma osteoblasts (ATCC, population numbers 14-17) in Dulbecco's modified Eagle medium (DMEM) supplemented with 10\% fetal bovine serum (FBS; Hyclone, South Logan, UT, USA) and 1\% penicillin/ streptomycin (P/S; Hyclone) were seeded at a density of 3500 cells $/ \mathrm{cm}^{2}$ and placed in an incubator under standard cell culture conditions $\left(37^{\circ} \mathrm{C}, 5 \% \mathrm{CO}_{2}, 95 \%\right.$ humidified air $)$ for three days. After the desired time period, cells were fixed using formaldehyde 4\% (Sigma Aldrich, St. Louis, MO, USA), stained with 4',6-diamidino-2-phenylindole (DAPI, ATCC), and counted under fluorescence microscopy (Zeiss Axiovert 200M Light Microscope; Carl Zeiss, Thornwood, NY, USA) in five random fields (averaged for each substrate).

\section{Coculture assays}

To investigate the density of both normal and cancerous osteoblasts when cocultured, normal osteoblasts and cancerous osteoblasts (described above) were pre-stained with the fluorescent dyes Vybrant DiO and Vybrant DiD (Molecular Probes, Eugene, OR, USA), respectively, and then seeded simultaneously in a media consisting of $50 \%$ DMEM and 50\% ObM (as described above) at a density of 750 cells $/ \mathrm{cm}^{2}$ (for each cell type) on either uncoated Ti or Ti coated with the high dose of Se in an incubator under standard cell culture conditions. Media was exchanged and cells were observed under fluorescence microscopy at 4, 17, 24, 40, 53 , and 65 hours. Cells were counted under fluorescence microscopy in five random fields and were averaged for each substrate.

\section{Statistical analysis}

Experiments were conducted in triplicate and repeated three times. Data were collected and significant differences were assessed with the probability associated with one-tailed Student's $t$-tests.

\section{Results Surface characterization}

SEM images of the uncoated and Se-coated material surfaces demonstrated the presence of Se nanoclusters and an apparent cluster surface density that increased from the low-dose to the medium-dose and high-dose Se cases (Figure 1). The Se nanoclusters were approximately $80 \mathrm{~nm}$ in diameter. These Ti substrates will be referred to as uTi, Low-nSe-Ti, Medium-nSe-Ti and High-nSe-Ti for uncoated Ti, and low, medium, and high Se dose-coated Ti substrates, respectively.

The Se morphology on the substrates appeared to be identical by SEM before and after sonication as well as after UV treatment for 24 hours (data not shown).

Uncoated Ti substrates were hydrophilic with an average water contact angle of approximately $55^{\circ}$. Importantly, coating Ti with selenium nanoclusters made the Ti surfaces more hydrophobic (Figure 2).

\section{Cell experiments}

\section{Separate cell culture assays}

After three days of culture, normal healthy osteoblast densities significantly increased on High-nSe-Ti compared to uTi and Low-nSe-Ti (Figures 3 and 4).

In contrast, for cancerous osteoblasts, after three days, cell densities were significantly higher on uTi and Low-nSe-Ti than on High-nSe-Ti (Figures 5 and 6). Specifically, cancerous osteoblast densities on Medium-nSe-Ti and High-nSe-Ti were significantly lower than on Low-nSe-Ti. Cancerous osteoblast

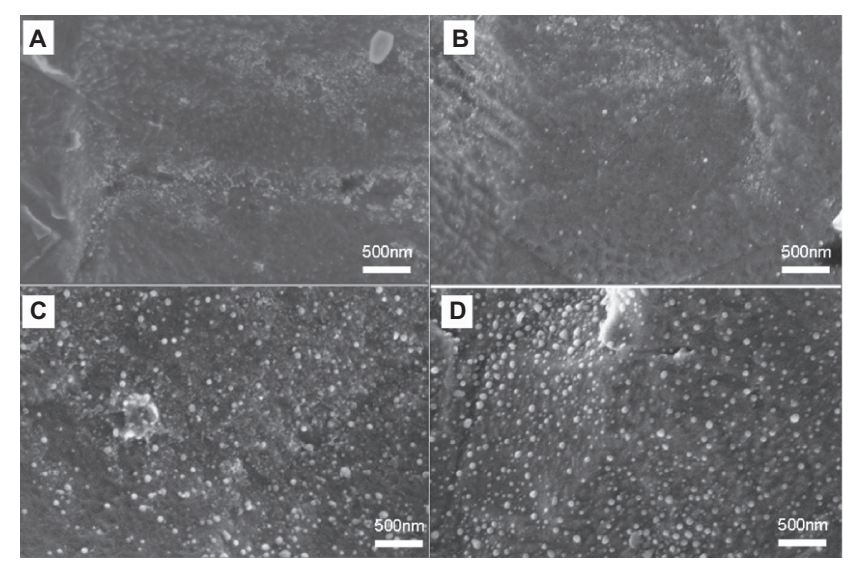

Figure I Representative SEM images of uncoated Ti A) and Se-coated Ti with low B) medium C) or high D) doses of Se nanoclusters.

Note: Scale bars are $500 \mathrm{~nm}$.

Abbreviations: Se, selenium; SEM, standard error of mean; Ti, titanium. 


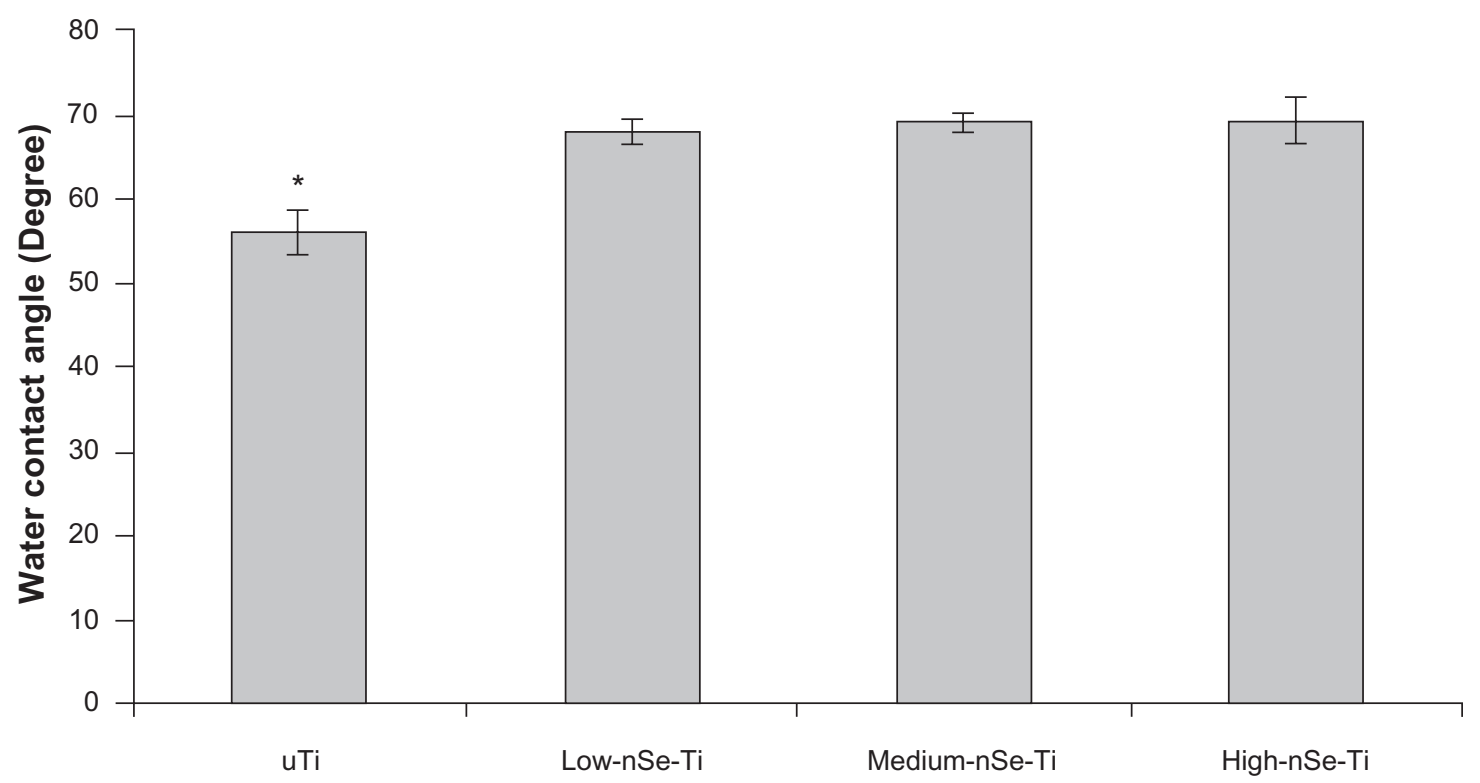

Figure 2 Water contact angles on the uncoated and Se-coated Ti substrates. Contact angles increased on the substrates coated with selenium nanoclusters. Notes: Data $=$ mean $\pm \mathrm{SEM} ; \mathrm{N}=3 ; * \mathrm{P}<0.05$ compared to all the coated substrates. There was no significant difference among the contact angles on the coated substrates. Abbreviations: Se, selenium; SEM, standard error of mean; Ti, titanium.

densities on High-nSe-Ti wer also significantly lower than on Medium-nSe-Ti (Figures 5 and 6).

\section{Coculture assays}

Coculture experiments were conducted only for two types of substrates, uTi (control) and High-nSe-Ti (which is the Se-coated substrate that had the highest normal healthy osteoblast density and the lowest cancerous osteoblast density from individual cell experiments). On the uncoated Ti substrates, cancerous osteoblast densities increased with time while healthy osteoblast densities did not change significantly among the different time points (Figure 7).

In contrast, significantly increased normal healthy osteoblast densities were observed after 53 and 65 hours when cocultured on High-nSe-Ti substrates suggesting a

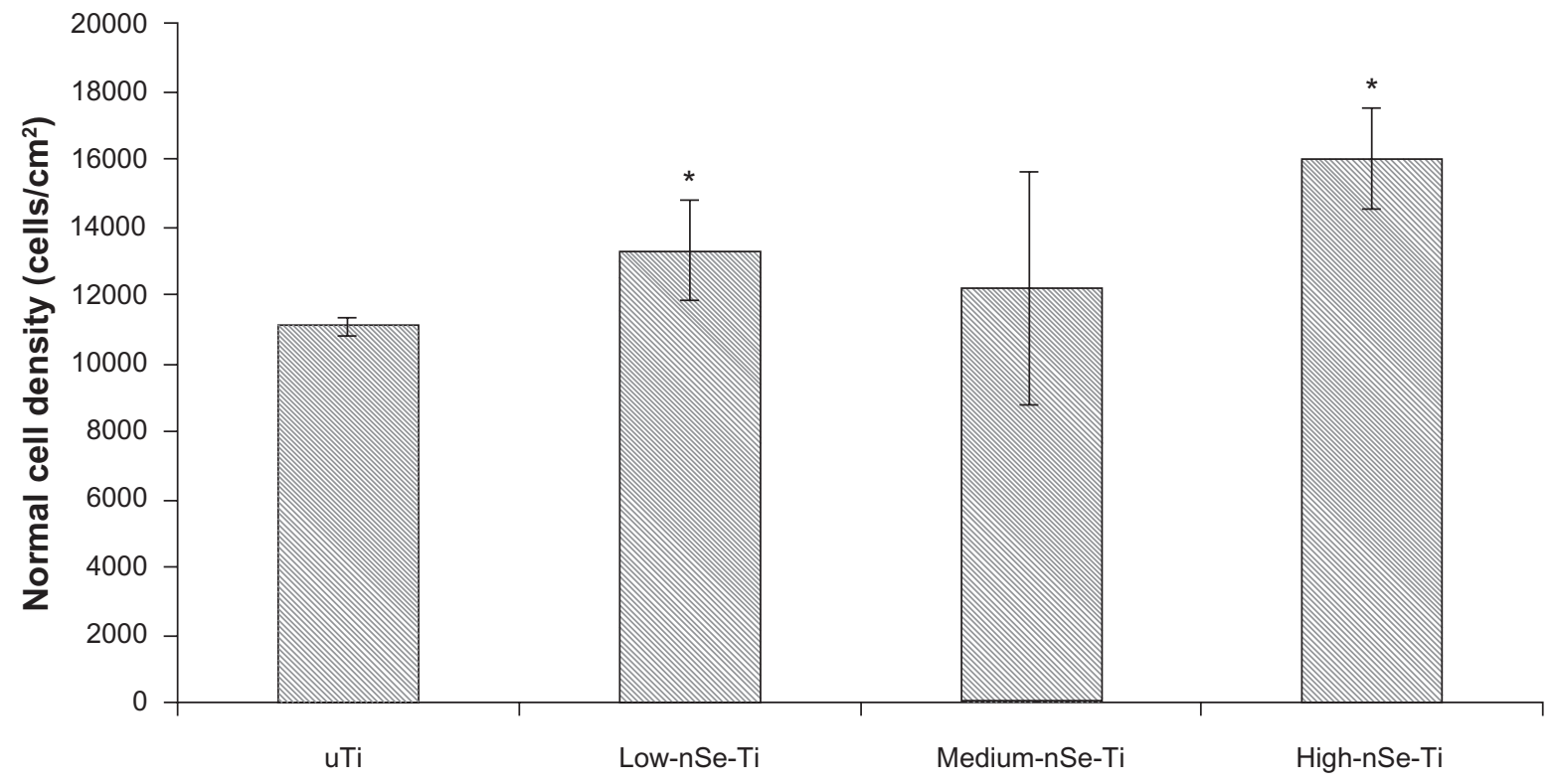

Figure 3 Normal osteoblast densities increased on Se-coated Ti substrates after three days of culture.

Notes: Data $=$ mean \pm SEM; $N=3 ; * P<0.05$ compared to $u T i$.

Abbreviations: Se, selenium; SEM, standard error of mean; Ti, titanium; uTi, uncoated Ti. 

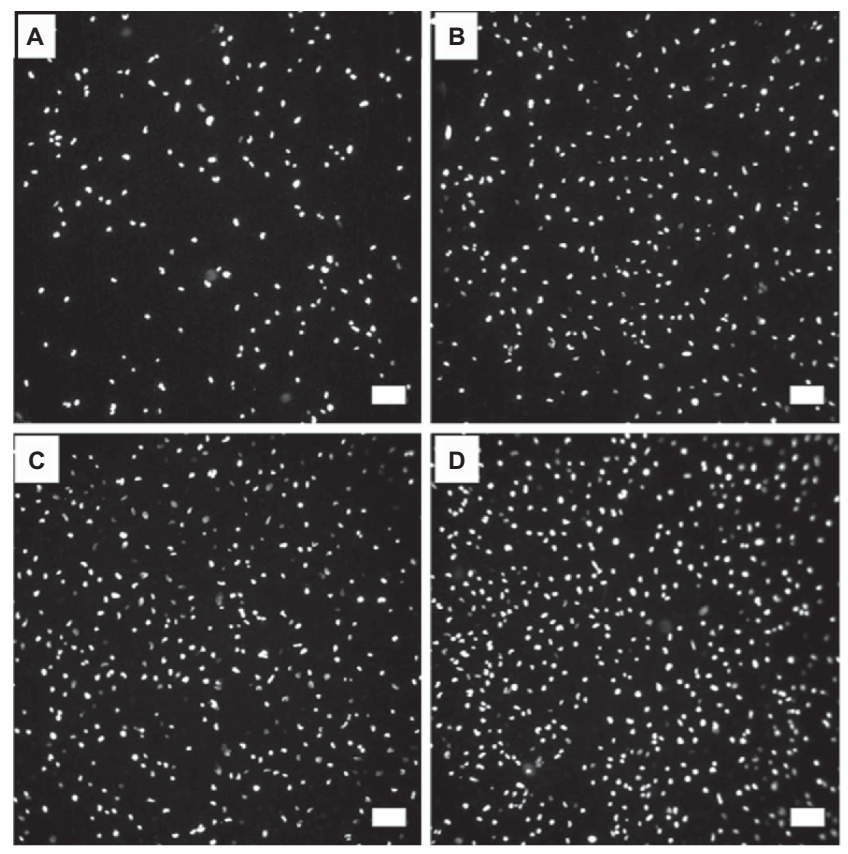

Figure 4 Fluorescence microscopy images of normal healthy osteoblasts stained with DAPI after three days of culture on uTi A) Low-nSe-Ti B) Medium-nSe-Ti C) and High-nSe-Ti D) Scale bars are $100 \mu \mathrm{m}$.

Abbreviations: DAPI, ; Se, selenium; SEM, standard error of mean; Ti, titanium; uTi, uncoated $\mathrm{Ti}$.

more favorable environment for healthy than cancerous osteoblasts on Se-coated Ti (Figure 8). Importantly, there was no significant change in cancerous cell densities on High-nSe-Ti among the different time points of the present study.

\section{Discussion}

Creating nanostructured surfaces to enhance osteoblast functions (including collagen, alkaline phosphatase, and calcium deposition) has been reported in a number of studies. For example, nanostructured (formulations with grain sizes less than $100 \mathrm{~nm}$ ) metals, ceramics, and polymers have been shown to enhance osteoblast adhesion, proliferation and differentiation..$^{9-14}$ In particular, Ti, Ti6Al4V, and CoCrMo with nanorough surfaces have been shown to enhance osteoblast adhesion compared to conventional (formulations with grain sizes greater than $100 \mathrm{~nm}$ ) respective metal surfaces..$^{10}$ For example, nanophase alumina (23 nm grain size) and nanophase titania ( $32 \mathrm{~nm}$ grain size) showed greater osteoblast adhesion compared to conventional, microphase alumina (177 nm grain size) and titania (2120 nm grain size). ${ }^{14}$ In addition, nanotube patterns on polycarbonate urethane (PCU) were demonstrated to decrease macrophage (cells that contribute to harmful chronic inflammation) density. ${ }^{15}$ Nanostructured $\mathrm{ZnO}$ and $\mathrm{TiO}_{2}$ surfaces were shown to decrease the adhesion and colonization of Staphylcoccus epidermidis which is the leading bacteria infecting orthopedic implants. ${ }^{16}$

Here, we used an anticancer implant material created by nanorough surface features on $\mathrm{Ti}$ using Se which is a trace element naturally found in the human body that has been shown to prevent various types of cancer from occurring and/or developing. ${ }^{5-7,17-35}$ The goal of this work was to demonstrate the potential of Se-containing nanostructured implant surfaces to support healthy osteoblast functions but inhibit cancerous osteoblast functions. To achieve this goal, we precipitated adherent Se nanoclusters by a colloidal-phase reaction on clean Ti surfaces. Various Se nanocluster densities were achieved by varying the $\mathrm{Se}$ concentration in the synthesis solutions. Ultrasonication

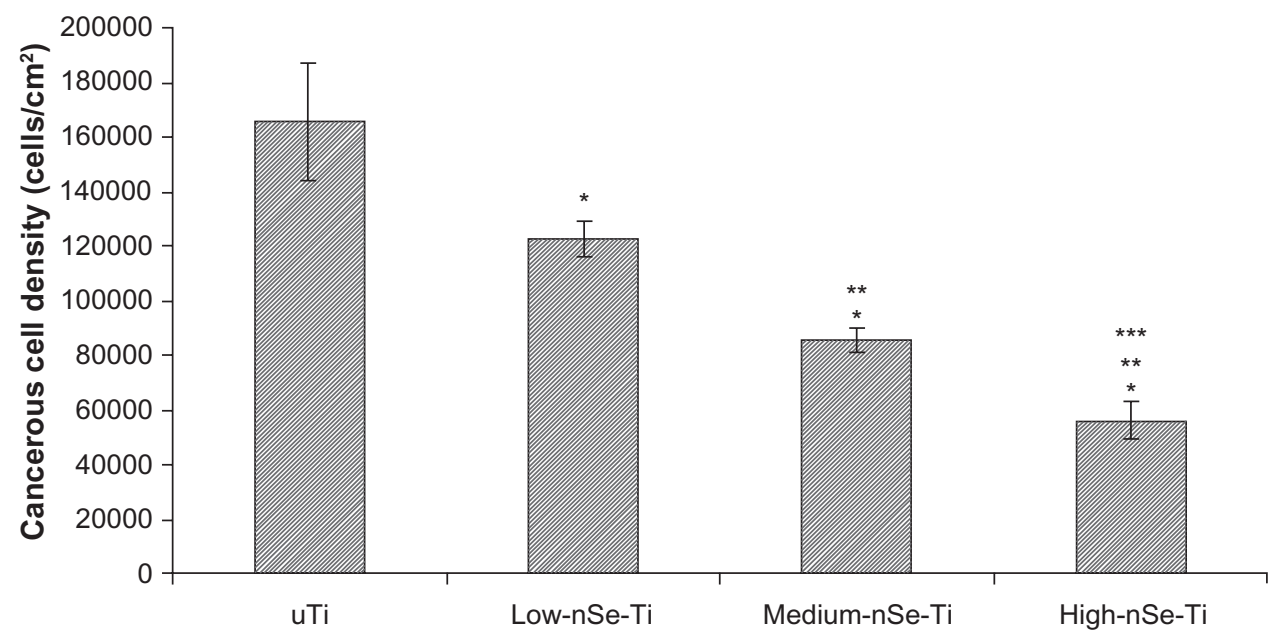

Figure 5 Decreased cancerous osteoblast densities on the Se-coated substrates after three days of culture.

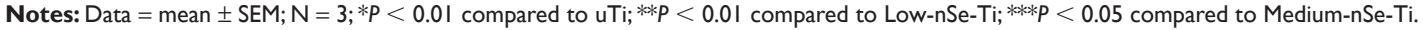

Abbreviations: Se, selenium; SEM, standard error of mean; Ti, titanium. 

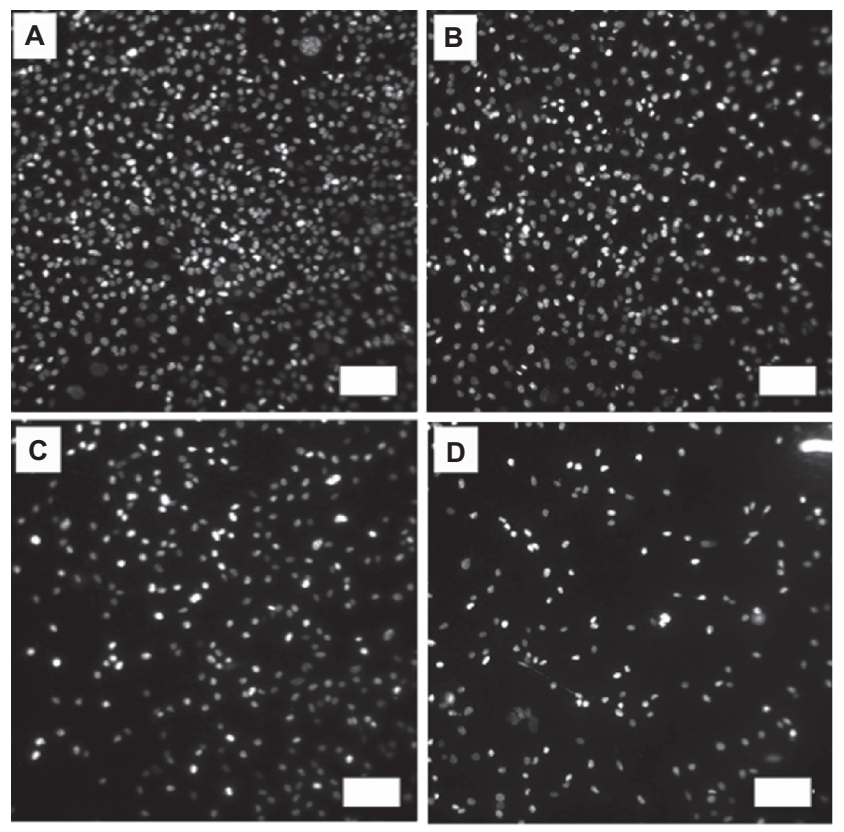

Figure 6 Fluorescence microscopy images of cancerous osteoblasts stained with DAPI after three days of culture on uTi A) Low-nSe-Ti B) Medium-nSe-Ti C) and High-nSe-Ti D).

Note: Scale bars are $100 \mu \mathrm{m}$

Abbreviations: DAPI, ; Se, selenium; SEM, standard error of mean; Ti, titanium.

tests demonstrated that Se nanoclusters strongly adhered to the Ti surfaces.

When the Se-coated substrates were used in separate cell culture experiments, normal bone cell proliferation increased while cancerous bone cell proliferation decreased compared to the uncoated Ti substrates. The increased normal bone cell proliferation is likely attributed to the greater number of nanofeatures on the Ti substrates coated with $\mathrm{Se}$ nanoclusters. This is because studies have demonstrated that increased implant nanoscale surface roughness led to greater adsorption of proteins (such as fibronectin and vitronectin) which mediate osteoblast adhesion. ${ }^{12,13}$

Importantly, this study also showed that the competitive proliferation of cancerous bone cells was inhibited on Ti-coated with Se nanoclusters. In single cell culture experiments, the inhibitory effect was dose-dependent; a higher dose of Se nanocluster coating density resulted in a greater inhibited cancerous bone cell proliferation.

The mechanism of Se-induced inhibited bone cell cancer growth is likely complex and remains to be elucidated. However, our previous results have indicated that soluble Se formulations released in cell culture media inhibited cancerous osteoblast growth while it did not have any effects on the growth of normal healthy osteoblasts. Therefore, it is likely that the biologically active species decreasing cancer cell density is soluble Se, either selenide or selenite, gradually released from the biologically inert $\mathrm{Se}^{0}$ nanoclusters in the presence of cell culture components. Some of the differences in cell growth may also be related to the modest changes observed in surface energy and hydrophilicity upon Se

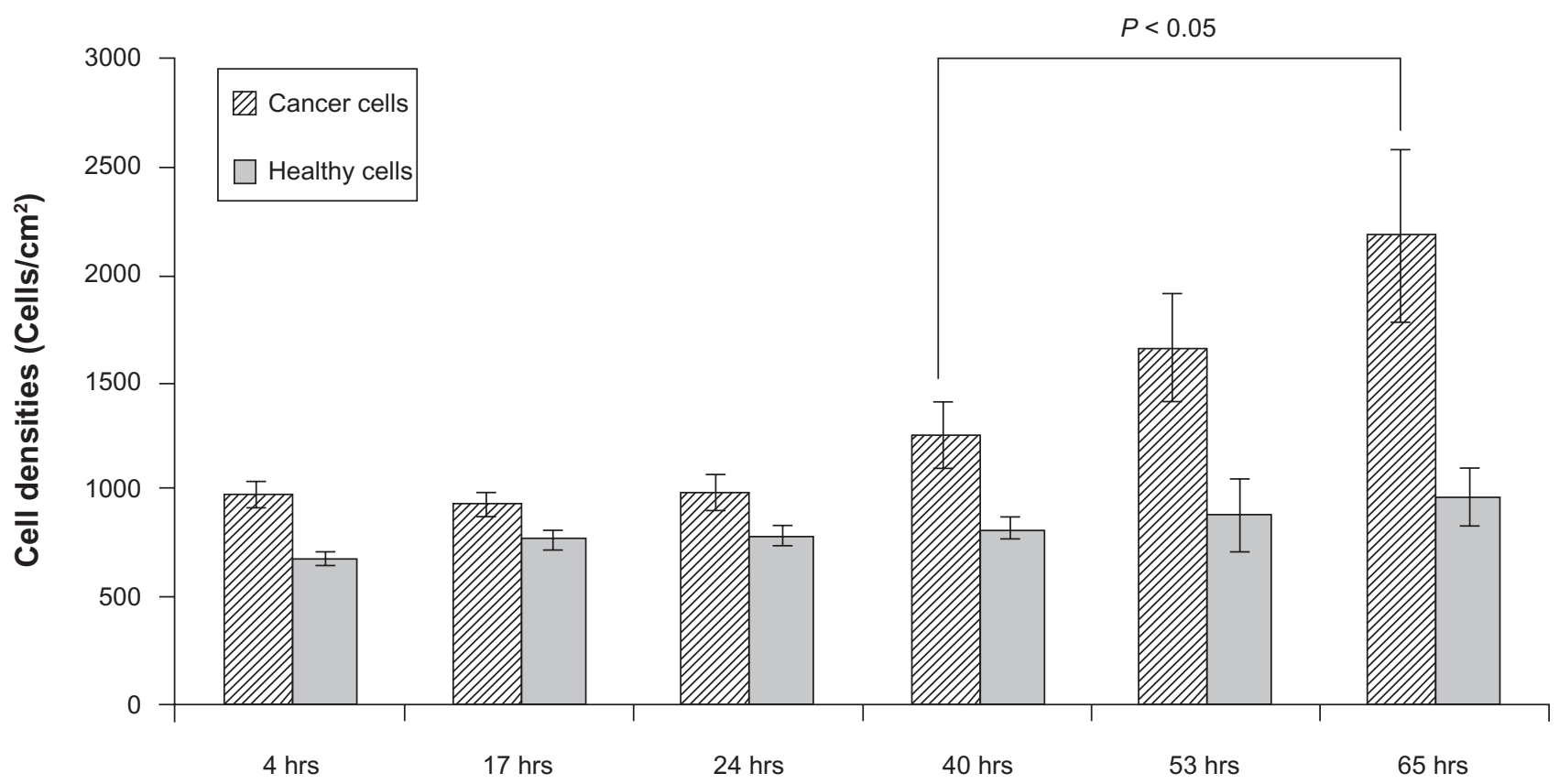

Figure 7 Increased cancerous osteoblast density after 65 hours of coculturing cancerous and healthy osteoblasts on uncoated Ti. Healthy osteoblast densities showed no significant change on uncoated $\mathrm{Ti}$.

Notes: $\mathrm{Data}=$ mean $\pm \mathrm{SEM} ; \mathrm{N}=3$.

Abbreviations: Se, selenium; SEM, standard error of mean; Ti, titanium. 


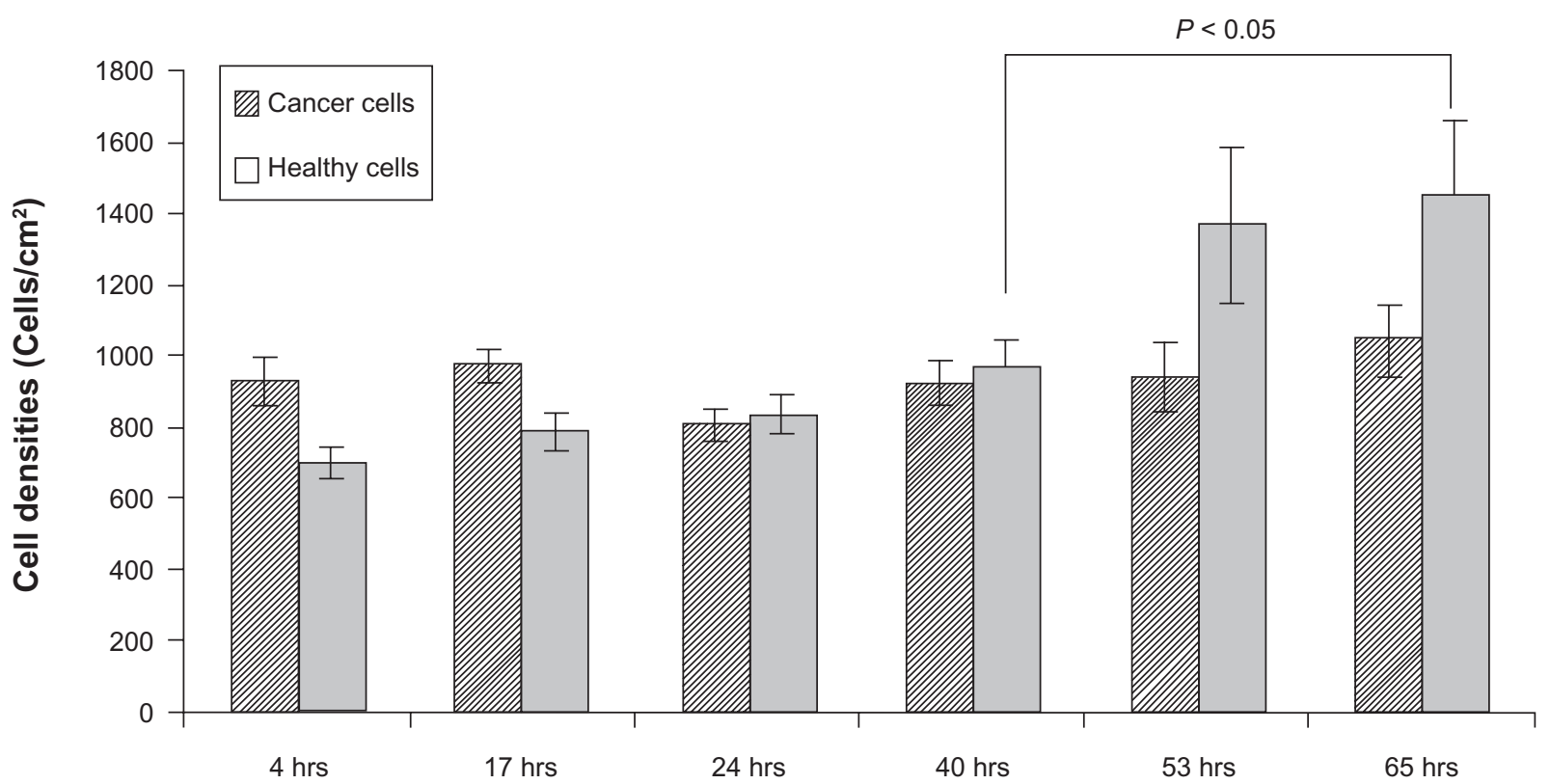

Figure 8 Increased healthy osteoblast density after 53 and 65 hours of coculturing cancerous and healthy osteoblasts on High-nSe-Ti. Cancerous osteoblasts did not show any significant difference in density on Se-coated Ti.

Notes: Data $=$ mean \pm SEM; $N=3$.

Abbreviations: Se, selenium; SEM, standard error of mean; Ti, titanium.

doping. Trends may also be related to the presently reported changes in hydrophobicity of the Se-coated compared to uncoated Ti samples. In the clinical situation where cancer cells are not completely removed during surgery, one will encounter situations where both normal healthy osteoblasts and cancerous osteoblasts are present at the implant site. Therefore, coculture experiments were conducted here in which both cancerous osteoblasts and normal osteoblasts were seeded together on either uncoated Ti or high dose Secoated Ti. For the first time, we report two interesting results: (i) on the uncoated Ti substrates, cancerous osteoblast density increased with time while healthy osteoblast density did not change significantly over the tested time period; and (ii) on the Se-coated Ti substrate, cancerous osteoblast density did not significantly change while healthy osteoblast density significantly increased after 53 and 65 hours.

It is intriguing that normal osteoblasts did not proliferate on uTi in the presence of cancerous osteoblasts. Although more investigation is needed, this could be due to the competition for nutrients by these cells and implant space occupied by the cancerous cells that inhibited the proliferation of normal healthy osteoblasts. Importantly, on the Ti coated with a high amount of Se nanoclusters, healthy osteoblast proliferation was enhanced after 53 and 65 hours while the proliferation of cancerous osteoblasts was inhibited during these time periods. In this study, we used the same seeding densities for both normal and cancerous osteoblasts. However, in clinical situations where cancerous osteoblasts are present at the implant site, as the result of incomplete tumor removal, most likely there will be more healthy osteoblasts than cancerous osteoblasts. Therefore, the trend demonstrated here (ie, decreased cancerous osteoblast and increased normal osteoblast densities) may be amplified leading to a faster integration of the implant into healthy bone and a stronger osteoblast cancerous inhibitory effect.

\section{Conclusions}

This study showed that Se nanocluster coatings on Ti can transform a normal orthopedic material into a cancerinhibiting implant. The coating densities are controllable by varying reagent concentration in the simple fabrication process described here. This work showed that, in the range of Se doses tested, cancerous osteoblast functions were inhibited, while healthy osteoblast functions were promoted when cultured separately or together on the same substrate. Further in vitro and in vivo studies should be conducted to examine the potential of Se nanocluster coatings for improving orthopedic implants.

\section{Acknowledgments}

The authors thank Prof. Derek Stein (Department of Physics, Brown University) for discussions on the design and 
implementation of the coculture experiments. The authors thank the Hermann Foundation for funding. The authors report no conflicts of interest in this work.

\section{References}

1. American Cancer Society. Cancer Statistics. 2008. Available from: http://www.cancer.org/docroot/STT/STT_0.asp. Accessed on December 2nd, 2009.

2. Tran PA, Sarin L, Hurt RH, Webster TJ. Titanium surfaces with adherent selenium nanoclusters as a novel anticancer orthopedic material. J Biomed Mater Res A. 2009; Nov 15. Epub ahead of print.

3. Tran PA, Sarin L, Hurt RH, J WT. Opportunities for nanotechnologyenabled bioactive bone implants. J Mater Chem. 2009;19:2653-2659.

4. McDowell L. Minerals in Human Nutrition. Amsterdam, The Netherlands: Elsevier; 2003.

5. Combs GFJ, Combs SB. The Role of Selenium in Nutrition. Orlando, FL: Academic Press; 1986.

6. Navarro-Alarcon M, Lopez-Martinez MC. Essentiality of selenium in the human body: relationship with different diseases. Sci Total Environ. 2000;249(1-3):347-371.

7. Apostolou S, Klein JO, Mitsuuchi Y, et al. Growth inhibition and induction of apoptosis in mesothelioma cells by selenium and dependence on selenoprotein SEP15 genotype. Oncogene. 2004;23(29):5032-5040.

8. Combs GF Jr. Impact of selenium and cancer-prevention findings on the nutrition-health paradigm. Nutr Cancer. 2001;40(1):6-11.

9. Webster T. Nanophase ceramics: the future of orthopedic and dental implant material. In: Ying J, editor. Nanostructured Materials. New York, NY: Academy Press; 2001. p. 125-166.

10. Webster TJ, Ejiofor JU. Increased osteoblast adhesion on nanophase metals: Ti, Ti6Al4V, and CoCrMo. Biomaterials. 2004;25(19): 4731-4739.

11. Webster TJ, Ergun C, Doremus RH, Siegel RW, Bizios R. Enhanced functions of osteoblasts on nanophase ceramics. Biomaterials. 2000;21(17):1803-1810.

12. Webster TJ, Ergun C, Doremus RH, Siegel RW, Bizios R. Specific proteins mediate enhanced osteoblast adhesion on nanophase ceramics. J Biomed Mater Res. 2000;51(3):475-483.

13. Webster TJ, Schadler LS, Siegel RW, Bizios R. Mechanisms of enhanced osteoblast adhesion on nanophase alumina involve vitronectin. Tissue Eng. 2001;7(3):291-301.

14. Webster TJ, Siegel RW, Bizios R. Osteoblast adhesion on nanophase ceramics. Biomaterials. 1999;20(13):1221-1227.

15. Kim JY, Khang D, Lee JE, Webster TJ. Decreased macrophage density on carbon nanotube patterns on polycarbonate urethane. J Biomed Mater Res A. 2009;88(2):419-426.

16. Colon G, Ward BC, Webster TJ. Increased osteoblast and decreased Staphylococcus epidermidis functions on nanophase $\mathrm{ZnO}$ and $\mathrm{TiO}_{2}$. J Biomed Mater Res A. 2006;78(3):595-604.

17. Lu J, Jiang C, Kaeck M, Ganther H, Ip C, Thompson H. Cellular and metabolic effects of triphenylselenonium chloride in a mammary cell culture model. Carcinogenesis. 1995;16(3):513-517.
18. Painter EP. The chemistry and toxicity of selenium compounds, with special reference to the selenium problem. Chem Rev. 1941;28(2): 179-213.

19. Combs GF Jr, Gray WP. Chemopreventive agents: selenium. Pharmacol Ther. 1998;79(3):179-192.

20. Clark LC, Dalkin B, Krongrad A, et al. Decreased incidence of prostate cancer with selenium supplementation: results of a double-blind cancer prevention trial. Br J Urol. 1998;81(5):730-734.

21. Bakir M, Yaseen T, Sarheel A, Othman I. The determination of selenium concentration in blood and tumour tissues of breast cancer patients in Syria using instrumental neutron activation analysis. Journal of Radioanalytical and Nuclear Chemistry. 2004;260(3):607-612.

22. Liu JZ, Zhang BZ, Milner JA. Dietary selenite modifies glutathione metabolism and 7,12-dimethylbenz(a)anthracene conjugation in rats. J Nutr. 1994;124(2):172-180.

23. Kaeck M, Lu J, Strange R, Ip C, Ganther HE, Thompson HJ. Differential induction of growth arrest inducible genes by selenium compounds. Biochem Pharmacol. 1997;53(7):921-926.

24. Lu J, Pei H, Ip C, Lisk DJ, Ganther H, Thompson HJ. Effect on an aqueous extract of selenium-enriched garlic on in vitro markers and in vivo efficacy in cancer prevention. Carcinogenesis. 1996;17(9):1903-1907.

25. Ronai Z, Tillotson JK, Traganos F, et al. Effects of organic and inorganic selenium compounds on rat mammary tumor cells. Int J Cancer. 1995;63(3):428-434.

26. Clark LC, Combs GF Jr, Turnbull BW, et al. Effects of selenium supplementation for cancer prevention in patients with carcinoma of the skin. A randomized controlled trial. Nutritional Prevention of Cancer Study Group. JAMA. 1996;276(24):1957-1963.

27. Redman C, Scott JA, Baines AT, et al. Inhibitory effect of selenomethionine on the growth of three selected human tumor cell lines. Cancer Lett. 1998;125(1-2):103-110.

28. Buser D, Nydegger T, Oxland T, et al. Interface shear strength of titanium implants with a sandblasted and acid-etched surface: a biomechanical study in the maxilla of miniature pigs. J Biomed Mater Res. 1999;45(2):75-83.

29. Wei WQ, Abnet CC, Qiao YL, et al. Prospective study of serum selenium concentrations and esophageal and gastric cardia cancer, heart disease, stroke, and total death. Am J Clin Nutr. 2004;79(1):80-85.

30. Combs G, Clark L. Selenium and cancer. In: Heber D, Blackburn G, Go VLW, Milner J, editors. Nutritional Oncology. New York, NY: Academic Press; 1999. p. 215-222.

31. Zhuo H, Smith AH, Steinmaus C. Selenium and lung cancer: a quantitative analysis of heterogeneity in the current epidemiological literature. Cancer Epidemiol Biomarkers Prev. 2004;13(5):771-778.

32. Menter DG, Sabichi AL, Lippman SM. Selenium effects on prostate cell growth. Cancer Epidemiol Biomarkers Prev. 2000;9(11):1171-1182.

33. Rayman MP. Selenium in cancer prevention: a review of the evidence and mechanism of action. Proc Nutr Soc. 2005;64(04):527-542.

34. Clark LC, Cantor KP, Allaway WH. Selenium in forage crops and cancer mortality in US counties. Arch Environ Health. 1991;46(1):37-42.

35. Styblo M, Thomas DJ. Selenium modifies the metabolism and toxicity of arsenic in primary rat hepatocytes. Toxicol Appl Pharmacol. 2001;172(1):52-61.
International Journal of Nanomedicine

\section{Publish your work in this journal}

The International Journal of Nanomedicine is an international, peerreviewed journal focusing on the application of nanotechnology in diagnostics, therapeutics, and drug delivery systems throughout the biomedical field. This journal is indexed on PubMed Central, MedLine, CAS, SciSearch $\AA$, Current Contents ${ }^{\circledR} /$ Clinical Medicine,

\section{Dovepress}

Journal Citation Reports/Science Edition, EMBase, Scopus and the Elsevier Bibliographic databases. The manuscript management system is completely online and includes a very quick and fair peer-review system, which is all easy to use. Visit http://www.dovepress.com/ testimonials.php to read real quotes from published authors. 